Research Article

\title{
Effect of chronic alcohol consumption on the red blood cell count and RBC indices in the HIV infected patients on $\mathrm{d} 4 \mathrm{~T} / 3 \mathrm{TC} / \mathrm{NVP}$ drug regimen in Uganda
}

\author{
Godfrey S. Bbosa ${ }^{1}$, David B. Kyegombe ${ }^{2}$, William W. Anokbonggo ${ }^{1}$, \\ Aloysius Lubega ${ }^{1}$, Apollo Mugisha ${ }^{3}$, Jasper Ogwal-Okeng ${ }^{1}$
}

${ }^{1}$ Department of Pharmacology and Therapeutics, Makerere University College of Health sciences, Uganda ${ }^{2}$ Department of Pharmacology and Toxicology, Kampala International University School of Health Sciences, Busyenyi, Uganda

${ }^{3}$ Mulago Hospital Complex Clinical Chemistry Laboratory, Uganda

Received: 10 July 2013

Accepted: 21 July 2013

\section{*Correspondence to:} Dr. Godfrey S. Bbosa, Email: godfossa@yahoo.com/godfossa @gmail.com

(C) 2013 Bbosa GS et al. This is an open-access article distributed under the terms of the Creative Commons Attribution Non-Commercial License, which permits unrestricted non-commercial use, distribution, and reproduction in any medium, provided the original work is properly cited.

\begin{abstract}
Alcohol consumption is common problem in Uganda. Among the types of alcohols consumed include beers, spirits, liqueurs, wines and traditional brew. These alcohols are easily accessible and consumed by many people including the HIV infected patients who are on the d4T/3TC/NVP regimen. The aim of this study was to determine the effect of chronic alcohol intake on the red blood cell count (RBC) and the RBC indices in the HIV-infected patients on $\mathrm{d} 4 \mathrm{~T} / 3 \mathrm{TC} / \mathrm{NVP}$ regimen. It was a case control study that used a repeated measures design model where serial measurements of the red blood cell count (RBC) and RBC indices were determined at 3 month interval for 9 months. A total of $41 \mathrm{HIV}$ infected patients were recruited and grouped into two arms; the control group had 21 patients and the chronic alcohol group had 20 patients. The $\mathrm{RBC}$ and RBC indices of the whole blood were determined using automated hematological Coulter CBC-5 Hematology Analyzer system using standard procedures. The data was sorted into alcohol-use self reporting by WHO AUDIT tool and alcohol-use biomarkers groups. It was analysed using the SAS 2003 version 9.1 statistical package with the repeated measures fixed model. The means were compared using the student t-test. The mean MCV and MCH values in the chronic alcohol use group were higher than in the control group and there was a significant difference between the 2 groups $(\mathrm{p}<0.05)$ for both the WHO AUDIT tool group and chronic alcohol use biomarkers group. The mean RBC count, Hct, HGB and MCHC values in both the control and chronic alcohol use groups were within the normal reference ranges for both groups though the trend was lower in alcohol group. Chronic alcohol use affects the RBC and RBC indices in the HIV infected patients on d4T/3TC/NVP treatment regimen.
\end{abstract}

Keywords: Chronic alcohol use, RBC, RBC indices, HIV infected patients, ARVs

\section{INTRODUCTION}

Alcohol mainly ethanol is by far the most abused drug for centuries world over and it is consumed in various alcoholic beverages such as wines, beers, liqueurs, spirits and local traditional home-made brew. ${ }^{1-3}$ The World Health Organization (WHO) estimates that there are about 2 billion people worldwide who consume alcoholic beverages and 76.3 million people are reported to have diagnosable alcohol use disorders. ${ }^{4-6}$ Alcohol causes 1.8 million deaths $(3.2 \%$ of total deaths) and 5.2 million deaths are due to fatal injuries associated with alcohol use annually. The deaths and disabilities are reported to range from $1.6 \%$ for developing countries and $9.2 \%$ for 
developed countries. ${ }^{4-7}$ In Uganda, alcohol consumption is a serious problem and is ranked a top most country in alcohol consumption among the 189 WHO member countries and in the African region. ${ }^{8-11}$ It is reported that $57 \%$ of the total Ugandan population, especially the adults, consume alcohol and about $4 \%$ of these live in places where alcohol is sold. It is also reported that 19.47 liters of pure ethanol is consumed per capita annually. Consumption of traditional alcohols is a common problem especially in the lower class status of individuals and in most cases it is difficult to quantity because its locally made in peoples' homes. ${ }^{8-11}$ The use of alcohol in Uganda is widely accepted in social events and cultural ceremonies. $^{10-13}$

In the body, ethanol is broken down in the liver and the gastrointestinal tract (GIT) by the alcohol dehydrogenase (ADH) isoforms and aldehyde dehydrogenase (ALDH) enzyme isoforms, the cytochrome P4502E1 (CYP2E1), CYP1A2 and CYP3A4 $4^{14-18}$ and catalase enzymes to generate a number of potentially harmful byproducts such as acetaldehyde, acetate, reactive oxygen species (ROS) such as hydroxyl radicals, superoxide anion and hydroxyl radicals and fatty acid ethyl esters (FAEEs). ${ }^{14-}$

${ }_{18}$ The ethanol metabolites cause deleterious effects to the body tissues and organs including the bone marrow thus suppressing the blood cell production (hemopoiesis). ${ }^{19-21}$ Chronic ethanol use also interfere with the absorption folic acid, vitamin B12 and minerals like iron and copper that are required in the $\mathrm{RBC}$ production in the bone marrow thus leading to nutritional anemia. $^{19-22}$ Alcohol is also known to cause vacuolization in bone marrow cells and suppresses hematopoiesis and this is reflected in changes in the peripheral blood picture like changes in peripheral leukocytes, erythrocytes or other variables related to erythrocytes like packed cell volume (PCV) or hematocrit (Hct) and RBC indices. ${ }^{19,23-26}$ Among the $\mathrm{RBC}$ indices include the mean corpuscular volume (MCV), mean corpuscular hemoglobin (MCH) and the mean corpuscular hemoglobin concentration (MCHC) and hemoglobin concentration (HGB). The MCV is the average volume or size of the red blood cells or the ratio of hematocrit to the RBC count. It expresses the average size of the erythrocytes and indicates whether they are undersized, oversized or normal. The normal MCV ranges from 76 to $96 \mathrm{fL} \cdot{ }^{19,23-26}$ It is a key parameter in the classification of anemia as well as chronic alcohol use biomarkers. The $\mathrm{MCH}$ is the amount of hemoglobin in an average red blood cell. It measures the concentration or weight of hemoglobin in an average red blood cell and the normal values ranges from 20 to $33 \mathrm{pg} .{ }^{19,23-26}$ It can also be expressed as a ratio of hemoglobin/RBC. The $\mathrm{MCHC}$ is the ratio of hemoglobin weight to hematocrit and it defines the concentration of hemoglobin in $100 \mathrm{ml}$ of packed red blood cells. It is used to distinguish the normally colored cells from paler cells and hence in the classification of the different anemias as well as in determining causes. The normal values ranges from 32 to $36 \% .^{19,23-26}$ The other measures of RBC activity include the hemoglobin concentration (HGB) and the hematocrit (Hct). The HGB is amount of the pigment in red blood cells that contains iron and transports oxygen to the tissues. The normal values ranges from 12 to 18 g/dL. ${ }^{19,23-26}$ The Hct or the packed cell volume (PCV) measures the amount of space or volume of red blood cells taken up or occupied by the packed red blood cells in a given volume of centrifuged blood. It is used in determination of anemia and it is usually expressed as a percentage of the volume of the whole blood sample. The normal values ranges from 36 to $54 \% .^{19,23-26}$ However chronic alcohol use inhibits the bone marrow's ability to utilize iron in making hemoglobin and also can interfere with the absorption and incorporation of the vitamin B12 and folic acid in the body which leads to immature RBC's or WBC's. The resulting incomplete production of red blood cells leads to a defect in RBC maturation and hence macrocytosis and increased MCV as well as destruction of as many platelets as can be made in a day..$^{20,23-25,27,28}$ Also the prolonged use of $\mathrm{d} 4 \mathrm{~T}$, 3TC and NVP drugs that are nucleoside reverse transcriptase inhibitors (NRTI) in HIV infected patients may be associated with bone marrow suppression and therefore concurrent chronic ethanol use by these patients may worsen the condition of anemia (RBC cell count and RBC indices). The study investigated the effect of chronic alcohol intake on the RBC, PCV, Hct and the RBC indices in the HIV infected patients on $\mathrm{d} 4 \mathrm{~T} / 3 \mathrm{TC} / \mathrm{NVP}$ drug regimen in Uganda. The d4T/3TC/NVP drug regimen was selected because during the time of the study, it was one of the first line drug regimens available for the treatment of HIVinfected patients in the country.

\section{METHODS}

\section{Study design}

The study was a case-control study that used repeated measures design model that was carried out on the HIV infected patients who were exposed to chronic alcohol and at the same time, they were initiated on the $\mathrm{d} 4 \mathrm{~T} / 3 \mathrm{TC} / \mathrm{NVP}$ drug regimen [triomune 30 (lamivudine (3TC) $150 \mathrm{mg}$, nevirapine (NVP) $200 \mathrm{mg}$ and stavudine (d4T) $30 \mathrm{mg}$ tablets)] for the last 6 months.

\section{Study site and population}

The study was conducted at St. Raphael of St Francis hospital, Nsambya, Private clinic. The hospital handles about 1,500 HIV infected patients. A total of $41 \mathrm{HIV}$ infected patients who on $\mathrm{d} 4 \mathrm{~T} / 3 \mathrm{TC} / \mathrm{NVP}$ drug regimen were recruited. They were grouped into two arms with the first arm or the control group consisting of $21 \mathrm{HIV}$ infected patients who were self-reported for not being exposed to any type of alcohol or to chronic alcohol for the past one year using WHO alcohol use disorder identification test (AUDIT) tool. The second arm had 20 HIV infected patients who were self-reported to be exposed to chronic alcohol using the tool. 


\section{Inclusion criteria}

All the HIV infected patients who were included in this study were HIV positive, on $\mathrm{d} 4 \mathrm{~T} / 3 \mathrm{TC} / \mathrm{NVP}$ drug combination regimen for the last 6 months at the time of enrolment. The adherence rates of all the patients recruited were measured using the self-reporting adherence and the pill counts at scheduled visits and all had an adherence rate of above $95 \%$. This was to ensure that the patients were taking their drugs as per the prescription recommendation. Also those included were in the age range of 18 to 50 years old. In the test group, they must have been exposed to chronic alcohol at the time of recruitment and during the 9 months follow up study period and in the control group, they were not exposed to any type of alcohol at all or for the last 6 to 12 months. All the patients signed the consent form before enrolment in the study.

\section{Eligibility criteria and enrolment of study participants}

The study was conducted on the HIV infected patients who were initiated on the $\mathrm{d} 4 \mathrm{~T} / 3 \mathrm{TC} / \mathrm{NVP}$ drug regimen for the last 6 months. At the time of enrolment, a total of 41 HIV infected patients on d4T/3TC/NVP were screened for chronic alcohol use using the WHO Alcohol Use Disorder Identification Test (AUDIT) tool. The 20 patients (13 males and 7 females) were identified to consume alcohol chronically using the tool and were enrolled into the chronic alcohol use group after signing the consent forms. The 21 patients (17 males and 4 females) were identified by the tool as non-alcohol consumers by the tool and were enrolled in the control group after consenting. The WHO AUDIT is currently an important tool which is non-invasive and it's routinely used worldwide to screen patients on chronic alcohol consumption. $^{29}$ The AUDIT tool has a set of 10 questions, each with responses and scores which the individual responds by self-reporting. A total score of 815 indicates hazardous alcohol use, 16-19 indicates alcohol use problem and scores above 20 indicates alcohol use dependence. ${ }^{29}$ All the patients recruited in the chronic alcohol group had a total score of above 8 according to the WHO AUDIT tool interpretation of the scores. The patients enrolled in the control group had a total score value of less than 8 . However because the WHO AUDIT was not sensitive enough to actually detect some of the patients in the control group who were consuming ethanol chronically, the chronic alcohol-use biomarkers (GGT, MCV and AST/ALT ratio) were used to further sort out the patients in the control group who were being exposed to chronic alcohol and could not be detected by the WHO AUDIT tool. For the chronic alcohol-use biomarkers, simultaneous elevation of the GGT values above 55.0 UI, MCV values above $96 \mathrm{fL}$ and AST/ALT ratio above 2.0 were indicative of chronic ethanol use. About $1 \mathrm{~mL}$ of whole blood was collected from the cubital vein for all the patients for the analysis of the biomarkers using the automated hematological Coulter CBC-5 Hematology Analyzer system for MCV and the Cobas Intergra 400 Plus analyzer system for GGT, AST and ALT serum enzymes analysis. And these biomarkers were monitored throughout out the 9 month follow up period to ensure that there were no reverts and converts. Therefore the $41 \mathrm{HIV}$ infected patients were again grouped according to the chronic alcohol use biomarkers into 2 arms with the chronic alcohol use arm having 26 patients (22 males and 4 females) and the control group with 15 patients (8 males and 7 females). These HIV infected patients in both the control and chronic alcohol exposed group were followed-up for 9 months starting from March 2008 to November 2008. The baseline parameters at time 0 month just before they were initiated on the $\mathrm{d} 4 \mathrm{~T} / 3 \mathrm{TC} / \mathrm{NVP}$ drug regimen for all the patients that participated in the study were collected retrospectively from the patients records.

\section{Whole blood sample collection and processing}

The whole blood samples from the recruited HIV infected patients on $\mathrm{d} 4 \mathrm{~T} / 3 \mathrm{TC} / \mathrm{NVP}$ regimen were collected from cubital vein every 3 months for a period of 9 months. About $2 \mathrm{ml}$ of whole blood were collected from each patient's visit into EDTA-containing vacutainer for RBC count, PCV, Hct and RBC indices (MCV, HGB, MCH and $\mathrm{MCHC}$ ) determination.

\section{$R B C$ count, Hct and $R B C$ indices determination}

The study was carried out at Mulago National Referral Hospital Clinical Chemistry and Haematology laboratories using automated hematological Coulter CBC-5 Hematology Analyzer system using standard procedures. The total red blood cell (RBC) count, hematocrit (Hct) and the $\mathrm{RBC}$ indices including the $\mathrm{MCV}, \mathrm{HGB}, \mathrm{MCH}$ and $\mathrm{MCHC}$ were determined for both the control group and the chronic alcohol group. The print-out for each patient was made. The results were entered into the excel spreadsheet from where they were exported to SAS statistical package and analyzed. The results were compared with the standard laboratory reference values for each parameter analyzed.

\section{Data analysis}

The data was analyzed by SAS 2003 version 9.1 statistical package at $95 \%$ confidence interval. The repeated measures fixed model was used in the statistical data analysis. The t-test was used to compare the means RBC count, Hct, HBG and RBC indices in the chronic alcohol use group and the control group at different time intervals.

\section{Ethical consideration}

Study was approved by the Makerere University, Faculty of Medicine Higher Degrees, Research and Ethics Institution Review Board (IRB) (IRB\#-2007-060), IRB of St. Raphael of St Francis hospital, Nsambya (no. IRB 03: 
01/03/2008) where study participants were recruited from and Uganda National Council for Science and Technology (UNCST) (no. HS 387). In this study, a written informed consent was obtained from each patient and that all procedures used were in accordance with ethical standards of responsible committee on human experimentation (institutional or regional) and in accordance with Helsinki Declaration of 1975, as revised in 1983. They were given study code numbers which were used all through study period in order to protect their privacy and confidentiality.

\section{RESULTS}

The effect of chronic alcohol consumption on the red blood count, PCV, Hct and RBC indices of HIV infected patients on $\mathrm{d} 4 \mathrm{~T} / 3 \mathrm{TC} / \mathrm{NVP}$ treatment regimen using the chronic alcohol-use self reporting WHO AUDIT tool and chronic alcohol-use biomarkers during the 9 months follow-up period were determined (Table 1, 2 and 3). The mean RBC count in both the control and chronic alcohol use groups were within the normal reference ranges of $3.8-6.5 \times 10^{6} \mu 1$ in both the chronic alcohol-use self reporting WHO AUDIT tool and chronic alcohol-use biomarkers groups. Though generally the RBC count in the chronic alcohol use group were lower than in the control group in both groups throughout the 9 months follow up period. The difference was statistically significant $(p=0.03$ and $\mathrm{p}=0.048$ respectively) in the 9 months for both groups (table 1 and 2). However, there was no significant difference $(p \geq 0.05)$ in the mean overall RBC count between the control and chronic alcohol use groups for both groups (Table 3).

Table 1: Variation of mean red blood cell count $(\mathrm{RBC})$ and mean $\mathrm{RBC}$ indices with time for control and chronic alcohol-use group using WHO AUDIT tool during the 9 months period.

\begin{tabular}{|c|c|c|c|c|c|c|}
\hline \multirow{2}{*}{\multicolumn{2}{|c|}{$\begin{array}{l}\text { Mean RBC count and } \\
\text { RBC indices }\end{array}$}} & \multicolumn{4}{|c|}{ Time of follow-up (months) } & \multirow{2}{*}{ Ref. } \\
\hline & & 0 & 3 & 6 & 9 & \\
\hline \multirow{2}{*}{$\begin{array}{l}\mathrm{RBC} \pm \mathrm{SE} \\
\times 10^{6} \mu \mathrm{l}\end{array}$} & Control & $4.26 \pm 0.75$ & $4.43 \pm 0.59$ & $4.34 \pm 0.56$ & $4.34 \pm 0.64$ & \multirow{2}{*}{$3.80-6.50$} \\
\hline & Alcohol & $4.29 \pm 0.61$ & $4.27 \pm 0.53$ & $4.16 \pm 0.58$ & $3.91 \pm 0.56$ & \\
\hline \multicolumn{2}{|l|}{$p$-value } & 0.86 & 0.20 & 0.40 & 0.03 & \\
\hline \multirow{2}{*}{$\begin{array}{l}\mathrm{HGB} \pm \mathrm{SE} \\
(\mathrm{g} / \mathrm{dl})\end{array}$} & Control & $14.25 \pm 2.09$ & $14.84 \pm 1.93$ & $14.50 \pm 1.83$ & $14.09 \pm 1.88$ & \multirow{2}{*}{$12-18$} \\
\hline & Alcohol & $14.13 \pm 1.44$ & $14.59 \pm 1.74$ & $14.32 \pm 1.78$ & $13.65 \pm 1.78$ & \\
\hline \multicolumn{2}{|l|}{$p$-value } & 0.36 & 0.39 & 1.00 & 0.45 & \\
\hline \multirow{2}{*}{ Hct $\pm \mathrm{SE}(\%)$} & Control & $41.55 \pm 6.04$ & $42.71 \pm 5.55$ & $42.83 \pm 5.21$ & $40.25 \pm 4.92$ & \multirow{2}{*}{$36-54$} \\
\hline & Alcohol & $41.37 \pm 5.07$ & $42.20 \pm 4.95$ & $42.24 \pm 5.65$ & $38.69 \pm 6.00$ & \\
\hline \multicolumn{2}{|l|}{$p$-value } & 0.79 & 0.55 & 0.99 & 0.37 & \\
\hline \multirow{2}{*}{$\begin{array}{l}\mathrm{MCV} \pm \mathrm{SE} \\
\text { (fl) }\end{array}$} & Control & $96.26 \pm 9.69$ & $96.95 \pm 7.32$ & $99.16 \pm 8.09$ & $93.22 \pm 7.54$ & \multirow{2}{*}{$76-96$} \\
\hline & Alcohol & $100.10 \pm 7.17$ & $99.30 \pm 8.91$ & $101.85 \pm 9.29$ & $99.22 \pm 9.11$ & \\
\hline \multicolumn{2}{|l|}{$p$-value } & 0.19 & 0.31 & 0.29 & 0.04 & \\
\hline \multirow{2}{*}{$\begin{array}{l}\mathrm{MCH} \\
\pm \mathrm{SE}(\mathrm{pg})\end{array}$} & Control & $32.55 \pm 3.77$ & $33.70 \pm 3.01$ & $33.57 \pm 3.2$ & $32.64 \pm 3.3$ & \multirow{2}{*}{$27-32$} \\
\hline & Alcohol & $34.36 \pm 3.15$ & $37.44 \pm 14.01$ & $34.63 \pm 3.21$ & $35.08 \pm 2.46$ & \\
\hline \multicolumn{2}{|l|}{$p$-value } & 0.18 & 0.27 & 0.30 & 0.02 & \\
\hline \multirow{2}{*}{$\begin{array}{l}\mathrm{MCHC} \\
(\mathrm{g} / \mathrm{dl})\end{array}$} & Control & $34.31 \pm 1.36$ & $34.85 \pm 1.21$ & $33.87 \pm 0.69$ & $34.96 \pm 1.61$ & \multirow{2}{*}{$31-35$} \\
\hline & Alcohol & $34.23 \pm 1.4$ & $34.47 \pm 1.22$ & $33.98 \pm 1.03$ & $35.39 \pm 1.36$ & \\
\hline \multicolumn{2}{|l|}{$p$-value } & 0.86 & 0.31 & 0.81 & 0.38 & \\
\hline
\end{tabular}

Ref: Reference values; SE: standard error; RBC: red blood cell count; HGB: hemoglobin; MCV: mean corpuscular volume; Hct: hematocrit; MCH: mean corpuscular hemoglobin; MCHC: mean corpuscular hemoglobin concentration 
The mean HGB in the control and chronic alcohol use groups in both the chronic alcohol-use self reporting WHO AUDIT tool and chronic alcohol-use biomarkers groups were also within the normal range of $12-18 \mathrm{~g} / \mathrm{dl}$ but the levels were lower in the chronic alcohol use group as compared to the control group (Table 1 and $2)$. However the difference was statistically significant $(\mathrm{p}=0.02$ and $\mathrm{p}=0.005)$ in the 3 and 6 month respectively in the chronic alcohol-use biomarkers groups (Table 2). Though there was no significant difference $(p \geq 0.05)$ in the overall mean HGB levels between the control and chronic alcohol use groups (Table 3). The mean $\%$ Hct levels were also within the normal reference ranges of $36-54 \%$ (Table1 and 2). The $\%$ Hct in the control group were higher than in chronic alcohol use group in the chronic alcohol-use self reporting WHO AUDIT tool but the difference was statistically insignificant $(p \geq 0.05)$. However, in the chronic alcohol-use biomarkers group, the \% Hct were higher in the 3 and 6 months and were statistically significant $(p=0.03$ and $p=0.01$ respectively). Though however, there was no significant difference in the overall \% Hct levels between the 2 groups (Table 3 ). The mean MCV values in the chronic alcohol use group were higher than the reference ranges of $76-96 \mathrm{fl}$ and the control groups throughout the 9 months follow up period. The difference was statistically significant $(p=0.04)$ in the 9 month of the chronic alcohol-use self reporting WHO AUDIT tool (Table 1). In the chronic alcoholuse biomarkers group, there was a significant difference $(p=0.01$ and $p=0.0005)$ in the 0 and 6 month respectively (Table 2). And there was significant difference $(p=0.0047)$ in the overall mean total MCV values in the chronic alcohol-use self reporting WHO AUDIT tool (Table 3). The mean $\mathrm{MCH}$ values in both the chronic alcohol-use self reporting WHO AUDIT tool and chronic alcohol-use biomarkers groups were above the normal reference ranges of $27-32 \mathrm{pg}$ but the values in the chronic alcohol use group were higher than in the control group (Table 1 and 2). In the chronic alcohol-use self reporting WHO AUDIT tool, the mean $\mathrm{MCH}$ values were statistically significant $(\mathrm{p}=0.02)$ in the 9 month (Table 1). In the chronic alcohol-use biomarkers group, the mean $\mathrm{MCH}$ values were statistically significant $(\mathrm{p}=0.003, \mathrm{p}=0.0004$ and $\mathrm{p}=0.04)$ in 0,6 and 9 months respectively (Table 2 ). However, there was significant difference $(\mathrm{p}=0.0042)$ in the overall mean $\mathrm{MCH}$ value in the chronic alcohol-use self reporting WHO AUDIT tool between the control and chronic alcohol use groups (Table 3). The mean MCHC values in the chronic alcohol-use self reporting WHO AUDIT tool and chronic alcohol-use biomarkers group were within the normal reference range of $31-35 \mathrm{~g} / \mathrm{dl}$ in the $0,3,6$ and 9 month follow up period except in the 9 month in the chronic alcohol-use biomarkers group where it was higher than the normal reference ranges (Table 1 and 2). The mean MCHC values in the chronic alcohol use were lower as compared to the control group in the 0 and 3 months for the chronic alcohol-use self reporting WHO AUDIT tool and in 3 month in the chronic alcohol-use biomarkers group. However, there was no significant difference $(p \geq 0.05)$ between the chronic alcohol use and the control groups and in the overall mean MCHC values for both the chronic alcohol-use self reporting WHO AUDIT tool and chronic alcohol-use biomarkers groups (Table 1, 2 and 3 ).

Table 2: Variation of mean red blood cell count $(\mathrm{RBC})$ and mean $\mathrm{RBC}$ indices with time among the control and chronic alcohol-use group using alcohol-use biomarkers.

\begin{tabular}{|c|c|c|c|c|c|c|}
\hline \multirow{2}{*}{\multicolumn{2}{|c|}{$\begin{array}{l}\text { Mean } \mathbf{R B C} \text { count and } \mathbf{R B C} \\
\text { indices }\end{array}$}} & \multicolumn{4}{|c|}{ Time of follow-up (months) } & \multirow{2}{*}{ Ref. } \\
\hline & & 0 & 3 & 6 & 9 & \\
\hline \multirow{2}{*}{$\begin{array}{l}\mathrm{RBC} \pm \mathrm{SE} \\
\mathrm{x} 10^{6} \mu 1\end{array}$} & Control & $4.31 \pm 0.75$ & $4.42 \pm 0.65$ & $4.36 \pm 0.54$ & $4.38 \pm 0.59$ & \multirow{2}{*}{$3.8-6.5$} \\
\hline & Alcohol & $4.25 \pm 0.63$ & $4.31 \pm 0.50$ & $4.19 \pm 0.59$ & $4.00 \pm 0.62$ & \\
\hline \multicolumn{2}{|l|}{$p$-value } & 0.60 & 0.31 & 0.45 & 0.05 & \\
\hline \multirow{2}{*}{$\begin{array}{l}\mathrm{HGB} \\
(\mathrm{g} / \mathrm{dl})\end{array}$} & Control & $14.3 \pm 4.97$ & $14.67 \pm 1.94$ & $14.15 \pm 2.04$ & $14.01 \pm 1.67$ & \multirow{2}{*}{$12-18$} \\
\hline & Alcohol & $14.11 \pm 1.67$ & $14.75 \pm 1.63$ & $14.54 \pm 1.67$ & $13.80 \pm 1.92$ & \\
\hline \multicolumn{2}{|l|}{$p$-value } & 0.31 & 0.02 & 0.005 & 0.68 & \\
\hline \multirow{2}{*}{ Hct \pm SE $(\%)$} & Control & $41.83 \pm 5.62$ & $42.24 \pm 6.08$ & $41.89 \pm 5.67$ & $40.11 \pm 3.95$ & \multirow{2}{*}{$36-54$} \\
\hline & Alcohol & $41.17 \pm 5.55$ & $42.60 \pm 4.69$ & $42.84 \pm 5.31$ & $39.15 \pm 6.14$ & \\
\hline \multicolumn{2}{|l|}{$p$-value } & 0.59 & 0.03 & 0.01 & 0.53 & \\
\hline
\end{tabular}




\begin{tabular}{|c|c|c|c|c|c|c|}
\hline \multirow{2}{*}{$\begin{array}{l}\mathrm{MCV} \pm \mathrm{SE} \\
\text { (fl) }\end{array}$} & Control & $94.97 \pm 9.88$ & $96.38 \pm 7.59$ & $96.23 \pm 6.08$ & $92.17 \pm 7.51$ & \multirow{2}{*}{$76-96$} \\
\hline & Alcohol & $100.50 \pm 6.8$ & $99.20 \pm 8.41$ & $102.69 \pm 9.12$ & $98.25 \pm 8.32$ & \\
\hline p-value & & 0.01 & 0.09 & 0.0005 & 0.07 & \\
\hline \multirow{2}{*}{$\begin{array}{l}\mathrm{MCH} \\
\pm \mathrm{SE}(\mathrm{pg})\end{array}$} & Control & $32.14 \pm 3.84$ & $33.45 \pm 3.29$ & $32.48 \pm 2.44$ & $32.21 \pm 3.76$ & \multirow{2}{*}{$27-32$} \\
\hline & Alcohol & $34.44 \pm 3.04$ & $36.84 \pm 12.55$ & $34.93 \pm 3.27$ & $34.69 \pm 2.83$ & \\
\hline$p$-value & & 0.003 & 0.15 & 0.0004 & 0.04 & \\
\hline \multirow{2}{*}{$\begin{array}{l}\mathrm{MCHC} \\
\pm \mathrm{SE}(\mathrm{g} / \mathrm{dl})\end{array}$} & Control & $34.19 \pm 1.41$ & $34.82 \pm 1.26$ & $33.78 \pm 0.58$ & $34.88 \pm 1.64$ & \multirow{2}{*}{$31-35$} \\
\hline & Alcohol & $34.33 \pm 1.36$ & $34.56 \pm 1.27$ & $34.0 \pm 0.99$ & $35.33 \pm 1.41$ & \\
\hline$p$-value & & 0.88 & 0.91 & 0.46 & 0.11 & \\
\hline
\end{tabular}

Ref: Reference values, SE: standard error

Table 3: Effect of chronic alcohol consumption by the HIV infected patients on d4T/3TC/NVP treatment regimen on the mean RBC count and mean RBC indices using alcohol-use self reporting WHO AUDIT tool and alcohol-use biomarkers during the follow-up period.

\begin{tabular}{|llll|}
\hline $\begin{array}{l}\text { Mean RBC and RBC } \\
\text { indices }\end{array}$ & Control group & $\begin{array}{l}\text { Chronic alcohol } \\
\text { consumption }\end{array}$ & p value \\
\hline $\mathrm{RBC} \pm \mathrm{SEx} 10^{6} \mu \mathrm{l}$ & $4.31 \pm 0.146$ & $3.93 \pm 0.137$ & 0.0701 \\
\hline $\mathrm{HGB} \pm \mathrm{SE}(\mathrm{g} / \mathrm{dl})$ & $14.07 \pm 0.46$ & $13.82 \pm 0.43$ & 0.70 \\
\hline $\mathrm{Hct} \pm \mathrm{SE}(\%)$ & $39.93 \pm 1.38$ & $39.25 \pm 1.3$ & 0.72 \\
\hline $\mathrm{MCV} \pm \mathrm{SE}(\mathrm{fl})$ & $92.73 \pm 1.76$ & $100.12 \pm 1.66$ & 0.0047 \\
\hline $\mathrm{MCH} \pm \mathrm{SE}(\mathrm{pg})$ & $32.63 \pm 0.64$ & $35.35 \pm 0.6$ & 0.0042 \\
\hline $\mathrm{MCHC} \pm \mathrm{SE}(\mathrm{g} / \mathrm{dl})$ & $35.15 \pm 0.36$ & $35.34 \pm 0.34$ & 0.715 \\
\hline & $\mathbf{A l c o h o l}-$ use biomarkers & \\
\hline $\mathrm{RBC} \pm \mathrm{SEx} 10^{6} \mu 1$ & $3.93 \pm 0.23$ & $3.93 \pm 0.143$ & 0.999 \\
\hline $\mathrm{HGB} \pm \mathrm{SE}(\mathrm{g} / \mathrm{dl})$ & $13.98 \pm 0.57$ & $13.82 \pm 0.36$ & 0.813 \\
\hline $\mathrm{Hct} \pm \mathrm{SE}(\%)$ & $40.29 \pm 1.82$ & $39.11 \pm 1.15$ & 0.588 \\
\hline $\mathrm{MCV} \pm \mathrm{SE}(\mathrm{fl})$ & $96.4 \pm 2.87$ & $99.85 \pm 1.82$ & 0.319 \\
\hline $\mathrm{MCH} \pm \mathrm{SE}(\mathrm{pg})$ & $33.41 \pm 0.97$ & $35.35 \pm 0.61$ & 0.102 \\
\hline $\mathrm{MCHC} \pm \mathrm{SE}(\mathrm{g} / \mathrm{dl})$ & $34.66 \pm 0.5$ & $35.43 \pm 0.32$ & 0.21 \\
\hline
\end{tabular}

\section{DISCUSSION}

The low values of the mean RBC count in the chronic alcohol consumption group could have been due to the effect of ethanol effects and it metabolites that suppress the bone marrow and hence interferes with the hemopoietic process leading to incomplete production of red blood cells as well as also affecting the vitamin B12 absorption and storage leading to immature RBCs or WBCs. ${ }^{20,23-28,30}$ The slightly low mean RBC count values in the 0 month of follow up in the control group as compared to the chronic alcohol consumption group of the alcohol-use self reported group could have been due to the co-current medications both prescribed and selfmedicated like the herbal preparation ${ }^{31-36}$ that affects the 
bone marrow and HIV disease stress, these people are experiencing as well as parasitic diseases like malaria and other unknown underlying conditions that may affect the hematopoietic process and hence affect blood cell production in the group..$^{23-26,30}$ The low mean HGB values in the chronic alcohol consumption group could have been due to the alcohol inhibition of the bone marrow's ability to use iron in making hemoglobin. ${ }^{23-26,30}$ However, the chronic alcohol consumption by the HIV infected patients on $\mathrm{d} 4 \mathrm{~T} / 3 \mathrm{TC} / \mathrm{NVP}$ drug regimen may not significantly affect the mean HGB content of the patients. The low \% Hct in the chronic alcohol consumption group could have been due to the alcohol sedation of the bone marrow making it unable to produce as many RBCs or WBCs and this is reflected in changes in the peripheral blood picture like changes in peripheral leukocytes, erythrocytes or other variables related to erythrocytes like hematocrit (Hct) or packed cell volume (PCV). ${ }^{23-26,30}$ The high values of the mean MCV in the chronic alcohol consumption groups could have been due to the effect of alcohol on the vacuolization of the bone marrow cells and thus suppressing the process of hematopoiesis leading to incomplete production of red blood cells; causing a defect in RBC maturation that leads to macrocytosis (RBC enlargement) and increased Mean Corpuscular Volume (MCV). ${ }^{23-26,30,35,36}$ However the slightly higher values of the mean MCV in the control group could be due to the effect of the HIV disease process and or the ARVs which the patients are taking coupled with other underlying patients' body conditions. ${ }^{26,37-39}$ Alcohol consumption affects the mean MCV values and it is the reason as to why it is used as an alcohol-use biomarker. ${ }^{40-42}$ The high values of the $\mathrm{MCH}$ in the chronic alcohol consumption groups could have been due to the effect of alcohol in the vacuolization of the bone marrow cells and thus suppressing the process of hemopoiesis leading to incomplete production of red blood cells; causing a defect in RBC maturation that leads to macrocytosis (RBC enlargement) and increased Mean Corpuscular Volume (MCV) as well as an elevated $\mathrm{MCH} .{ }^{23-26,30}$ Therefore in this study, alcohol consumption affects the $\mathrm{MCH}$ values in the HIV infected patients on d4T/3TC/NVP drug regimen. The slightly high value of mean $\mathrm{MCHC}$ in the 9 month period of follow up in the chronic alcohol consumption group for both the alcohol-use self reported WHO AUDIT tool group and for the alcohol-use biomarkers group could have been due to the alcohol and its metabolites causing a defect in $\mathrm{RBC}$ maturation that leads to macrocytosis (RBC enlargement) and increased Mean Corpuscular Volume (MCV) as well as an elevated $\mathrm{MCH}$ and MCHC. ${ }^{23-26,30}$ Chronic ethanol use by the HIV infected patients on $\mathrm{d} 4 \mathrm{~T} / 3 \mathrm{TC} / \mathrm{NVP}$ drug regimen lowers the RBC counts, HBG, Hct (PCV) and slightly increases the $\mathrm{MCV}, \mathrm{MCH}$ and $\mathrm{MCHC}$ values during the 9 month period of follow up.

\section{CONCLUSION}

Chronic ethanol use by the HIV infected patients on d4T/3TC/NVP drug regimen lowers the RBC counts,
HBG, Hct (PCV) and slightly increases the MCV, MCH and $\mathrm{MCHC}$ hematological parameters during the 9 month period of follow up. Chronic alcohol use may exacerbate the effects of the d4T, 3TC and NVP adverse drug reactions to the bone marrow thus inhibiting the bone marrow's ability to utilize iron in making hemoglobin and also can interfere with the absorption and incorporation of the vitamin B12 and folic acid in the body which leads to immature RBC's thus effecting the RBC count and RBC indices observed in the study.

\section{ACKNOWLEDGEMENTS}

We would like to acknowledge the following contributors to the success of this work and without them; it would have been impossible to do this study including Prof. Florence Mirembe from the Dept of Pediatrics and Dr. Tugumisirize in the Dept of Pychiatry, Makerere University College of Health Sciences for the guidance and continued encouragement through the study period. We want to thank Sr. Justine Birungi, Sr. Plaxeda, Sr. Namugosa, Sr. Jesca and Dr. Kayima from the St. Raphael of St Francis hospital, Nsambya, Private clinic who assisted us in the recruitment of the subjects and the collection of blood samples from the patients. We want to thank the Director of St. Raphael of St Francis hospital, Nsambya and the Dr. Pius Okong, the chairman of IRB of the hospital for allowing us to conduct this study in the hospital. We also acknowledge the contribution of Dr. Norah Mwebaza and Mr. Dan Kibuule for all the support in this study.

\section{Funding: None}

Conflict of interest: None declared

Ethical approval: Approved by the local ethical committee [Faculty of Medicine Higher degrees, Research and Ethics committee of Makerere University Institution Review Board (IRB) (IRB\#-2007-060), IRB of St. Raphael of St Francis hospital, Nsambya (no. IRB 03: 01/03/2008) where the study participants were recruited from and the Uganda National Council for Science and Technology (UNCST)(no. HS 387)]

\section{REFERENCES}

1. Heath DB. Anthropology and alcohol studies: Current Issues. Annual Reviews Anthropology 1987;16:99-120.

2. Micheal, G., Alcohol health issues related to alcohol consumption. The place of alcohol in human culture., 1996: p. 1-22.

3. Wikipedia, Alcoholic beverage. Wikimedia Foundation Inc. USA. "http://en.wikipedia.org/wiki/ Alcoholic_beverage". 2009.

4. WHO, A Summary of Global Status report on Alcohol. Management of Sustance Dependence, Non-Communicable Diseases, World Health Organisation June 2001., 2001: p. 2-14.

5. WHO, Global Status Report on Alcohol 2004. 2004: Geneva, Switzerland. 
6. WHO, Alcohol and Injury in Emergency Department: Summary of the Report from the WHO Collaborative Study on Alcohol and Injuries. WHO Library Cataloguing-in-Publication Data, 2007: p. 111.

7. Parry, C.D.H. and S. Dewing, A public Health Approach to Addressing Alcohol-related Crime in South Africa. African Journal of Drug and Alcohol Studies. CRISA Publications., 2006. 5(1): p. 41-53.

8. Kafuko, A. and P. Bukuluki, Qualitative research in Uganda on knowledge, attitude and practices concerning alcohol. 2008, USAID, Health Communication, YEAH and Afford: Corporate Agreement number 617-A-00-07-00005-00.

9. Lwanga-Ntale, C., Drinking into deeper poverty: The new frontier for Chronic Poverty in Uganda. Chronic Poverty Research Center: Development Research and Training. Policy Brief No.1/2007., 2007.

10. Obot, I.S., Alcohol use and related problems in Subsaharan Africa. African Journal of Drug and Alcohol Studies. CRISA Publications., 2006. 5(1): p. 17-25.

11. YEAH, Alcohol Consumption in Uganda: Literature Review. (Young Empowered and Health -YEAH) http://www.yeahuganda.org/research/AlcoholConsu mption.pdf (Accessed on 22/07/09). 2007.

12. Jernigan, D.H. and I.S. Obot, Thirsting for the African market. African Journal of Drug and Alcohol Studies. CRISA Publications., 2006. 5(1): p. 57-68.

13. Ovuga, E. and C. Madrama, Burden of alcohol use in the Uganda police in Kampala district. African Health Sciences, 2006. 6(14-20.).

14. Edenberg, H.J., The role of alcohol dehydrogenase and aldehyde dehydrogenase variants:The genetics of alcohol metabolism. The Journal of the National Institute on Alcohol Abuse and Alcoholism., 2007. 30(1): p. 5-12.

15. Eng, M.Y., S.E. Luczak, and T.L. Wall, ALDH2, ADH1B and ADH1C genotypes in Asians: A literature Review. The Journal of the National Institute on Alcohol Abuse and Alcoholism., 2007. 30(1): p. 22-26.

16. Quertemont, E. and V. Didone, Role of acetaldyde in mediating the Pharmacological and Behavioral effects of alcohol. The Journal of the National Institute on Alcohol Abuse and Alcoholism., 2006. 29(4): p. 258-264.

17. Scott, D.M. and R.E. Taylor, Health-related effects of genetic variations of alcohol-metabolising enzymes in African Americans. The Journal of the National Institute on Alcohol Abuse and Alcoholism., 2007. 30(1): p. 18-20.

18. Zakhari, S., Overview: How is alcohol metabolised by the body? The Journal of the National Institute on Alcohol Abuse and Alcoholism., 2006. 29(4): p. 245-252.

19. Edith, L., et al., Effect of alcohol consumption on blood antioxidant nutrients and oxidative stress indicators. American Journal of Clinical Nutrition., 1994. 60: p. 255-261.

20. Fleming, M., S.J. Mihic, and R.A. Harris, Ethanol. Goodman Gilman's, the pharmacological basis of therapeutics. McGraw-Hill Medical publishing Division, New York. 10th ed. 2001(18): p. 429-442.

21. Haile, H.E., Booze and blood: The effect of acute and chronic alcohol abuse on the hematopoietic system. Clinical Laboratory Science, July-August 1998., 1998. 11(4): p. 229.

22. O'Neil, P., et al., Performance Evaluation of the Complete Blood Count and White Blood Cell Differential Parameters on the AcT 5diff Hematology Analyzer. Laboratory Hematology. Beckman Coulter, Inc, Diagnostics Division, Miami, Florida, USA. Carden Jennings Publishing Co., Ltd, 2001. 7: p. 116-124.

23. Balkaya, M., et al., Effects of Alcohol and Passive Smoking on Some Hematological Variables of Swiss Albino Mice. Turkish Journal of Veterinary Animal Science, 2005. 29: p. 241-250.

24. Chu, Y.C., Haematological Effects of Alcohol. Journal of the Hong Kong Medical Association, 1989. 41(1): p. 41-42.

25. Cook, R.T., Alcohol abuse, alcoholism, and damage to the immune system--a review. Alcoholism: Clinical Experimental Research, 1998. 22: p. $1927-$ 1942.

26. Latvala, J., Effect of alcohol consumption and acetaldehyde on blood cells and molecules. Acta University of Tampere. Thesis. http://acta.uta.fi/pdf/951-44-6095-2.pdf, 2004.

27. Anders, H., T. Boris, and W.I.s. centres, Biochemical markers of alcohol use and abuse: Experience from the pilot study of the WHO/ISBRA Collaborative Project on State and Trait Markers of Alcohol. Alcohol and Alcoholism., 1997. 32(2): p. 133-144.

28. Chalmers, D.M., et al., Sex-related differences in the haematological effects of excessive alcohol consumption. Journal of Clinical Patholology., 1980. 33: p. 3-7.

29. Babor, T.F., et al., The Alcohol Use Disorders Identification Test (AUDIT) Manual: Guidelines for Use in Primary Care. Second Edition. Department of Mental Health and Substance Dependence. World Health Organization 2001. WHO/MSD/MSB/01.6a., 2001: p. 4-32.

30. Gonzalez-Casas, R., E.A. Jones, and R. MorenoOtero, Spectrum of anemia associated with chronic liver disease. World Journal of Gastroenterology ISSN 1007-9327. www.wjgnet.com, 2009. 15(37): p. 4653-4658.

31. Antoniou, T. and A.L. Tseng, Interactions between recreational drugs and antiretroviral agents. HIV Program/Inner City Health, St. Michael's Hospital, Toronto, Ontario, Canada. Annals of Pharmacotherapy 2002. 36(10): p. 1598-613.

32. Brunton, L.L., J.S. Lazo, and K.L. Parker, Antiretroviral agents and treatment of HIV 
infection. Goodman and Gilman's The Pharmacological Basis of Therapeutics. 11th edition. 2006: p. 1273-1309.

33. Hoetelmans, R.M.W., Clinical Pharmacokinetics of Antiretroviral Drugs. AIDS Reviews., 1999. 1: p. 167-178.

34. Orrick, J.J., Antiretroviral drug interactions. Infectious Diseases: HIV/AIDS Primary care guide, Florida Aids Education and Training Centre, University of Florida., 2002. 7: p. 69-81.

35. Chavez, M.L., K.J. MacKinnon, and L.S. Swanson, Herbal - Drug Interactions. INET Continuing Education (InetCE), 2005. 9(10): p. 1-30.

36. Fugh-Berman, A., Herbal-Drug interactions. The Lancet, 2000;355:134-138.

37. Bartlett, J.G. and J.E. Gallant, Medical Management of HIV Infection. Johns Hopkins University School of Medicine. Johns Hopkins Medicine Health Publishing Business Group. Baltimore, USA. 20052006., 2006.

38. Lima, V.D., et al., Association between HIV-1 RNA Level and CD4 Cell Count Among Untreated HIVInfected Individuals. Research and Practice. American Journal of Public Health. 2009. 99(S1): p. S193-S196.
39. Madge, S., et al., HIV in Primary Care: An essential guide to HIV for GPs, practice nurses and other members of the primary healthcare team. Medical Foundation for AIDS and Sexual Health (MedFASH) 2004. London, UK., 2005: p. 11-67.

40. SAMHSA, The role of Biomarkers in the treatment of alcohol use disorders. Substance Abuse and Mental Health Service Administration: US Center for substance abuse treatment. 2006. 5(4).

41. Sawyer, S.M., et al., Laboratory Measures of Alcohol (Ethanol) Consumption: Strategies to Assess Drinking Patterns with Biochemical Measures. Biological Research for Nursing, 2003. 4(3).

42. Szabo G, et al. Levels of Carbohydrate-Deficient Transferrin according to Gender and Age in a Small Town in Hungary. CEMED 2009;3(2):319-25.

doi:10.5455/2319-2003.ijbcp20131004

Cite this article as: Bbosa GS, Kyegombe DB, Anokbonggo WW, Lubega A, Mugisha A, OgwalOkeng J. Effect of chronic alcohol consumption on the red blood cell count and RBC indices in the HIV infected patients on $\mathrm{d} 4 \mathrm{~T} / 3 \mathrm{TC} / \mathrm{NVP}$ drug regimen in Uganda. Int J Basic Clin Pharmacol 2013;2:528-36. 